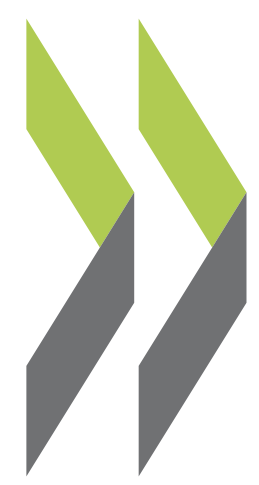

\title{
The Amsterdam Watershed:
}

\section{How School Design is} Changing and Why the Next

\section{Randall Fielding}

\author{
Ten Years are Critical
}




\section{THE AMSTERDAM WATERSHED}

\section{How school design is changing and why the next ten years are critical}

Bruce Jilk is an architect and educational planner at KKE Architects in Minneapolis, Minnesota (United States). He also is a well-known speaker, educator and planner, and one of his projects, The School of Environmental Studies in Apple Valley, Minnesota, received the 1999 New American High School Award by the US Department of Education. Jilk also was chair at the American Institute of Architects' (AIA) November 2000 conference in Amsterdam (Netherlands), where he introduced the conference on "Innovative Alternatives in Learning Environments," as a watershed event; he anticipates the period from 2000 to 2010 to be a crucial decade for educational planning. Jilk tossed out numerous "mind grenades," talked about the future of schools, presented projects and conducted tours of several schools and another built beneath residential apartments. The common theme involved schools closely integrated with the community and the sharing of spaces. Below are Jilk's answers to follow-up questions submitted by 11 conference attendees from three different countries.

Randy Fielding: Bruce, you referred to the recent conference in Amsterdam, "Innovative Alternatives in Learning Environments," as a watershed event, and the period from 2000 to 2010 as a watershed decade for educational planning. Why is this a watershed conference and decade?

Bruce Jilk: As suggested by the conference name, "Innovative Alternatives in Learning Environments," this event focused on schools that are "outside the box" and most of them did not exist ten years ago. For example, in 1990 the United States did not have one single charter school. Now we have more than 2000 . And consider that home schooling is one of the fastest growing educational industries. These changes are reflective of the larger macro-shift in civilisation - from an industrial society to a knowledge society.

The Club of Budapest ${ }^{1}$ studies this shift, which they say began around 1860, and tells us that we are beginning the decade of the "Consequent Phase." That is to say the next ten years are critical in forming the future. I took the liberty of renaming this phase "The Watershed Decade," a term

Alpha High School, Oregon, United States
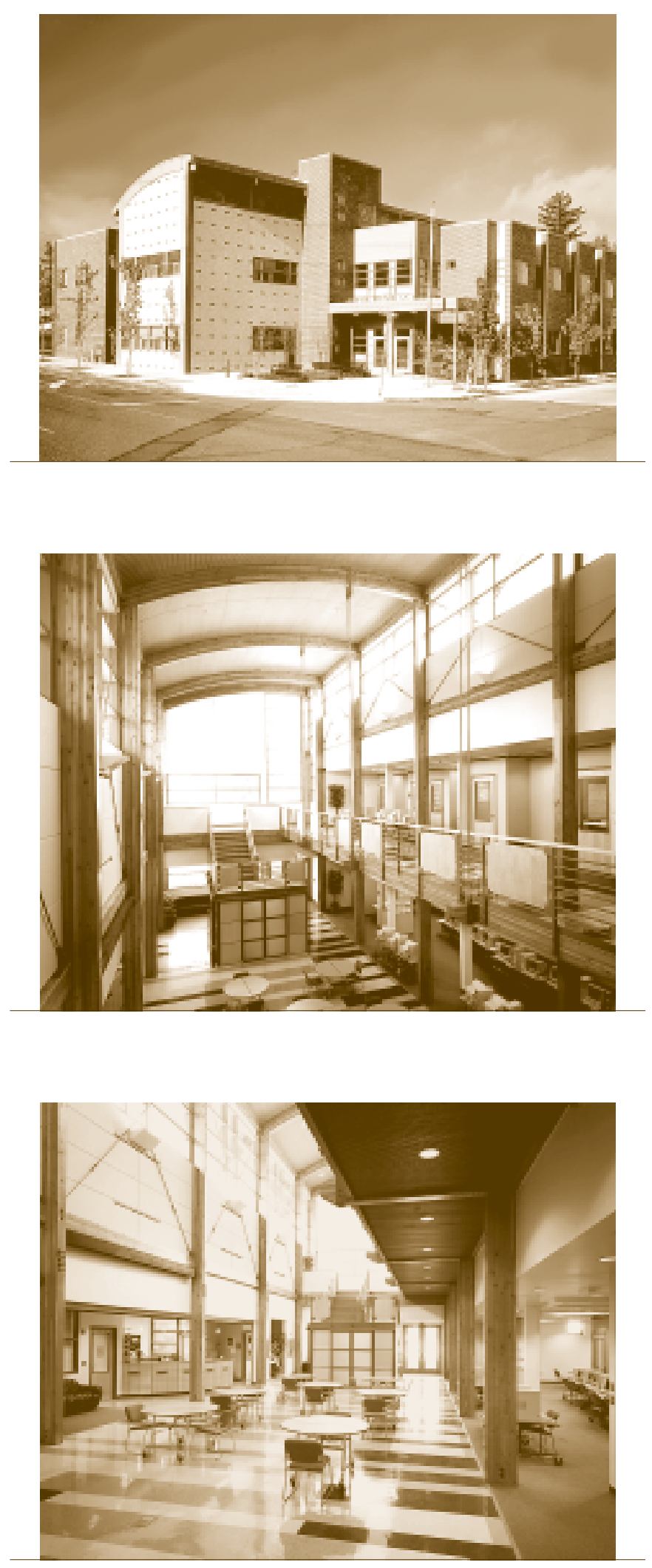
I feel says the same thing only with a more optimistic connotation. Because the event in Amsterdam disclosed the aspects of this cultural change as it effects the world of learning, it seemed appropriate to extend that title to the event itself, Amsterdam Watershed.

RF: The Heinavaara Elementary School in Finland is one of the most notable projects with which you have been involved since the School of Environmental Studies (SES) ${ }^{2}$ in Minnesota. How have your ideas evolved since working on the two projects?

BJ: The School of Environmental Studies is an optional public suburban high school for 400 students and was designed seven years ago in collaboration with HGA Inc. Heinavaara is a 190-student public elementary school in Finland, north of Helsinki, near the Russian border. It was designed two years ago in collaboration with the Cuningham Group.

Heinavaara works at several levels. First of all, it is designed to be supportive of a child's learning experience. The spaces are organised to enhance both the connections amongst children as well as their cognitive, social, emotional, physical and other developmental experiences. It also works as part of the community's economic development. By developing new wood construction methods - for Finland - the local construction industry is being educated, positioning them to lead future endeavours in Finland and Russia. The project also serves as a community centre ${ }^{3}$.

Bill Brenner: What will happen to the classroom in the coming years, and what will schools look like?

BJ: Will we still have classrooms? A common place where a common group of people engage in a common way with a common subject at a common time will be justification for the classroom. However, as we embrace lifelong learning where anybody can learn anything, anyway, at anytime and anyplace - there will be a diminished need for classrooms.

The educational philosophies of Perennialism and Essentialism 4 are deeply imbedded in our concepts of education. They grew with our current cultural view starting about 2000 BC. However as we shift into a knowledge society, these concepts will lose their cultural grounding. My best guess is that the classroom as the primary place of learning will shift to a secondary place of learning between 2020 and 2030. This is a concern because the life expectancy of new schools is around 70 years.

In the very near future we will see the design of classrooms flourish like never before. This is driven by a basic feature of human nature. It is a form of "irrational exuberance." It is similar to the response people have knowing someone is dying; you
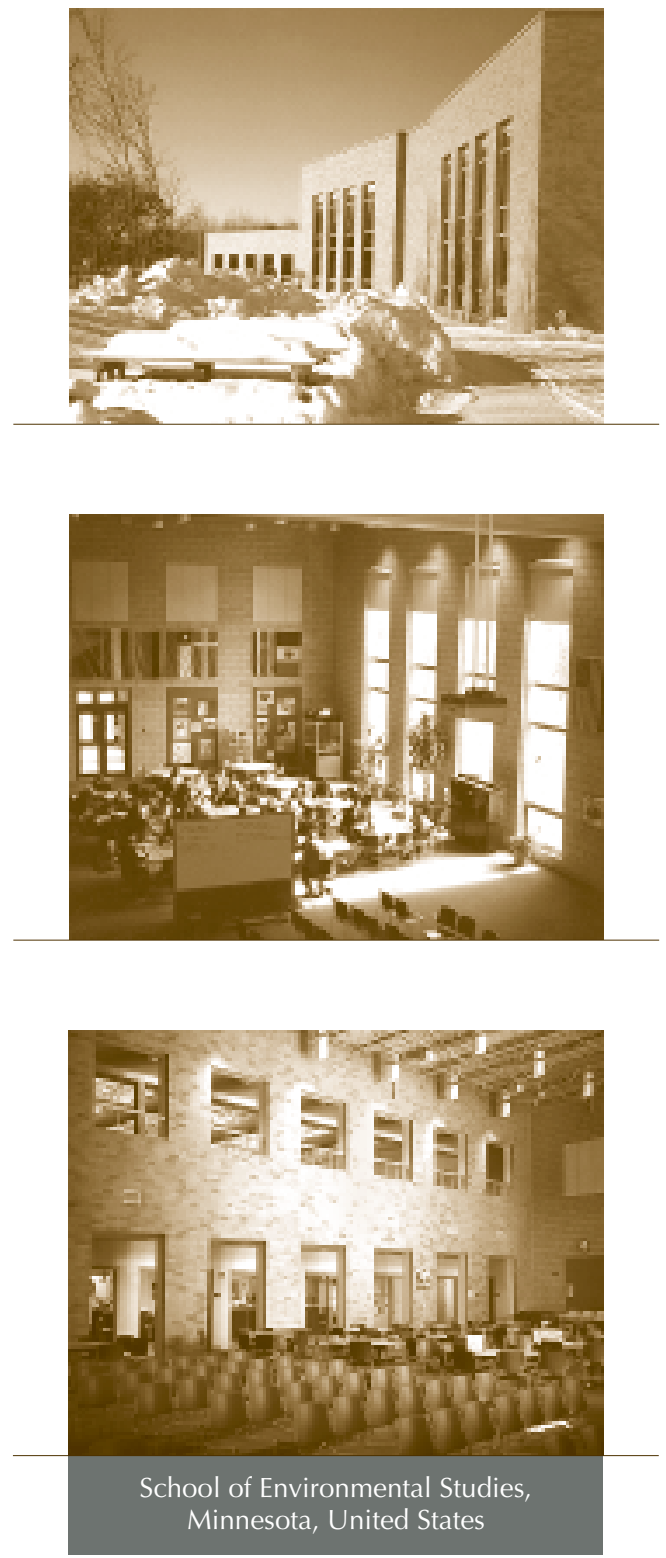

13

1. Founded in 1993, The Club of Budapest is an international association dedicated to developing a new way of thinking and a new ethics that helps tackle social, political, economic and ecological challenges of the $21^{\text {st }}$ century; http://www.club-ofbudapest.org

2. Plans for this school can be viewed at http://www.designshare.com

3. Heinavaara serves as a community centre functionally and symbolically in several ways. The community uses the gymnasium, central library/media area and cafeteria on evenings and weekends. The project also is located at a high point in a new residential development. The building's timber entry canopy reflects the heritage of the Karelian building style, unique to the region.

4. Perrenialism is defined as: despite differing environments, human nature remains the same everywhere; hence education should be the same for everyone. Essentialism is defined as: learning that, by its very nature, involves hard work and often unwilling application. 
go out of your way to show your deepest caring. This exuberance is being played out in kindergarten to 12th grade schools by pretending classrooms are the centre of the universe. This phase will retract in ten years. In higher education, campuses are desperate to survive as seen by the flourish of "signature" architecture. Think of these buildings as tombstones.

The question "what will schools look like in the future?" is probably the most common and misunderstood aspect of what I have been working on. We talk about what is the best school design, we have conferences to discuss our ideas about this, and we give awards to those that fit our preconceptions. In our effort to simplify things we begin to think as if one size fits all. Most people will say they do not think this way, however, the pattern is there. Prototype schools are an example of this pattern. In the future, the traditional school will not be replaced by a new, better design, rather we will develop options to the traditional school. These options are the innovations we focused on in Amsterdam.

In the future we will continue to have traditional schools but fewer of them -, optional schools that are similar to traditional schools, and innovative alternatives. As to what they look like, it is safe to say that virtually any future design concept already exists today, in some form, somewhere on this earth.

Lia Burgers: As the meaning of learning is changing from passive to active, from static to dynamic, from insideoriented to outside, to lifelong learning and to global learning, is it still necessary to create educational systems that are surrounded by institutional walls and barriers?

BJ: One of the fundamental attributes of a knowledge society is the significance of connections or relationships amongst its elements. There is evidence of the convergence between the corporate world and the education world. The same is true for the home world. Any "walls" or "barriers" need to be examined to assure they enable and not inhibit these connections.

These are extremely challenging times for traditional institutions of education. We live in a culture of choice and there are many new choices. While traditional school and college growth parallels the population growth, growth in non-traditional options is expanding at about the rate of $40 \%$ per year. In my experience, traditional institutions of education are responding to this challenge, they are collaborating. Bottom line: no more isolation.

Charles H. Boney, Jr.: The classrooms we observed in Amsterdam were 20 to $50 \%$ smaller than standard US classrooms. The elementary school under two floors of

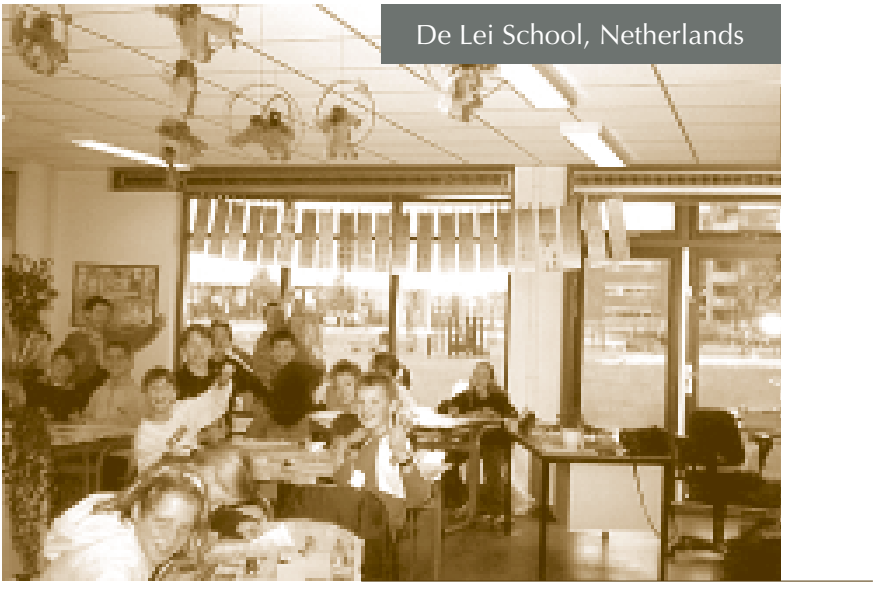

apartments had classrooms of 55 to 65 square metres; in the US we see 85 to $100 \mathrm{~m} 2$. Also, there are few ancillary spaces, but they made great use of corridor space for computers and storage. Do you think our American bias towards single-purpose spaces, i.e. corridors must always be corridors, and learning only occurs in the classroom, inhibits the educational opportunities in our buildings?

BJ: The classroom is primarily a teaching environment and, as a design, has little to do with learning; learning is a byproduct. Learning environments - spaces designed with learning as the primary goal - need to be multifunctional. They need to support formal learning, informal learning and resource learning. I call these the learning threads. The learning environment is a fabric made up of these threads. Creating single purpose spaces is barrier architecture, not enabling architecture.

CHB: We saw many well-maintained schools on our tours. Is this typical of the Netherlands or did we just see the newest schools where maintenance issues have not become apparent?

BJ: I have been in new schools in Baku that badly needed maintenance and old schools in Singapore that were pristine. We can find the same variations throughout the United States. So the question is primarily a cultural one and this makes any short answer quite difficult. I will offer one observation, however. Countries, states or communities where society sees the "big picture" and takes a "long view," such as in the Netherlands, will nurture their resources more carefully.

Prakash Nair: Do you subscribe to the traditional notion of learning as a conscious, independent activity or do you believe that learning is really a "by-product" or an accidental outcome of some other primary activity? 


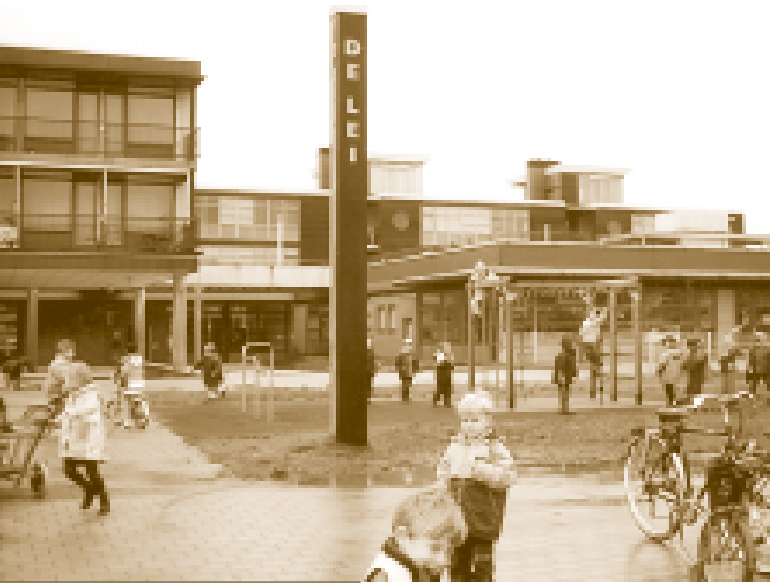

BJ: First, I need to adjust the question. Learning can be a conscious activity but not independent. Learning always has context. Also the learning that goes on in the traditional classroom is mostly a by-product of teaching but not necessarily accidental. So I think the question is better stated as "is learning a conscious activity or experiential?" I would clearly say it is both.

PN: If the latter is true, do you believe schools that are set up as primary learning places miss the mark altogether? In other words, have schools and school facilities, as we know them, become anachronisms in modern society or will they remain viable in the future with some periodic tweaking?

BJ: As I've said earlier, schools in modern society are teaching environments, and as places to teach, they hit the mark quite well. I've framed the discussion around the terms "Industrial Society" and "Knowledge Society." This question also involves the terms "Modern Society" and, by implication, "Post-modern Society." It will be constructive if we follow the latter terminology for a moment.

The Post-modern concept includes the modern within it; it does not cast it out. It is the modern world plus something more. And this is my point about schools. We still will have some traditional schools, which will be forever "tweaked," plus something more. Traditional schools will become only one of many choices, not the only one or even the primary one.

Arnie Glassberg: What role can an architect play in helping school boards move to an understanding of the importance of school design to learning?

BJ: School boards need to understand they are in the learning business, not the teaching business. I know I'm repeating myself, but this goes to the basic problem.

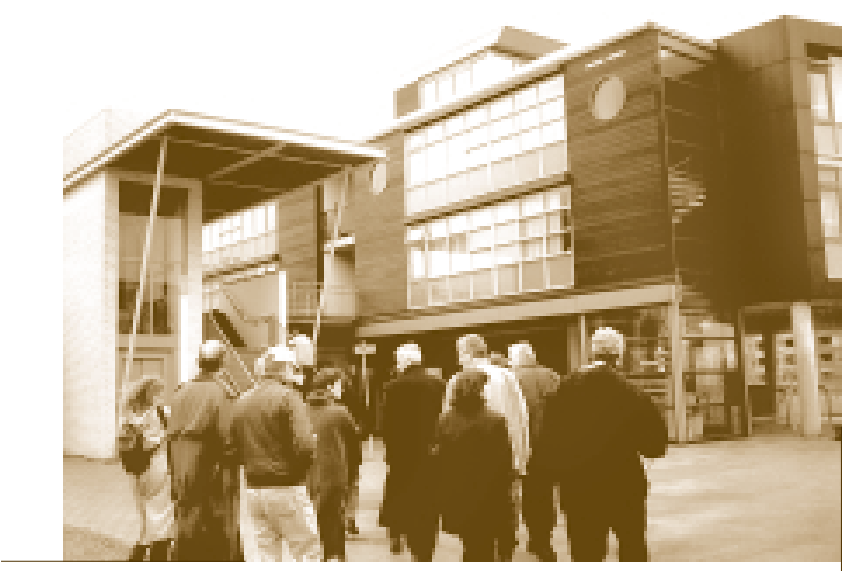

Remember what happened to the railroads in the United States? They thought they were in the railroad business not the transportation business. The decisions they made came from this perspective, were self-serving, and, as a result, they ended up mostly out of business.

Likewise, school boards (and teacher unions, textbook printers, school architects, etc.) need to stop making self-serving decisions and behave in the interest of a learning society. Just as railroads did not go away, schools and school boards will not go away. However, just as railroads have competitors and a smaller market share, so will public school systems. Architects will be of no help until they consider themselves part of a learning society; I doubt this will happen before their clients, the school systems, make this shift.

Andy Simpson: Knowing that new models are difficult, at best, to implement given constraints of facilities management, staff reluctance, local politics and other issues, what is your best advice to educational leadership (superintendents, board members and instructors) for navigating the current watershed?

BJ: I would advise people to buy into and follow a comprehensive process. I typically use the "design-down" process", but there are others. In addition: 1) be clear about the true purpose of the endeavour; 2) involve representatives of all stakeholders; 3) begin with the needs and expectations of the larger community; 4) agree on what is special about the project; and 5) be honest about learner expectations.

Everyone has ownership (not just the superintendent or architect) and you can never do enough communicating. Learn about other programmes by visiting them or have

5. For more information on the design-down process, visit http:// www.cefpi.org 
representatives from those programmes visit you. The effort needs leadership - that can come from anywhere but is best if it comes from the school system - and skilled facilitation. And, finally, it is essential that everyone make decisions around what is best for the child/learner.

Watch out for statements such as: "the school board won't approve," "the superintendent's job is at stake" or "this is outside the union agreement." None of these ideas are in the primary interest of the child.

Jack Lyons: Currently, the average age of our kindergarten to $12^{\text {th }}$ grade schools is 42 years. We know that the tempo of changes to the learning environment is increasing and that one of the hallmarks of excellent school design is adaptability. How can we provide the flexibility necessary without compromising the classroom environment?

BJ: Consistent with the question about the maintenance of Dutch schools, we need to invest our space, time and money in areas that go beyond just the immediate goals of any project. The way to do this is to step back and look at the bigger picture.

We typically build schools so physical elements outlive the functional. This functional obsolescence can manifest itself in two ways. First, the learning processes can change, and second, population shifts may make the need for the school obsolete.

In the first case, architects have used a variety of design strategies including movable walls, non-bearing partitions, modular mechanical and electrical systems, etc. In the second case, the strategy has been to predict the future uses and design with that in mind. I feel both of these approaches will have limited success and do not really look at the bigger picture; instead of designing schools, we should step back and design communities.

James LaPosta: The question that keeps occurring to me is "what if we are wrong?" There is an unfortunate history of architectural innovation in schools that utterly failed and I worry that we may be headed down that well-intentioned road again. The idea of learning spread throughout the community is appealing and well reasoned, but not six blocks from my Hartford office is a failed experiment in community integrated learning from the 1980s that recently was replaced by a more traditional facility. The costs of failure are so high - generations of children who only go through the system once - that we need certainty that what we do is right. How do we integrate the lessons from the past with the best thinking that the educational community can offer us?

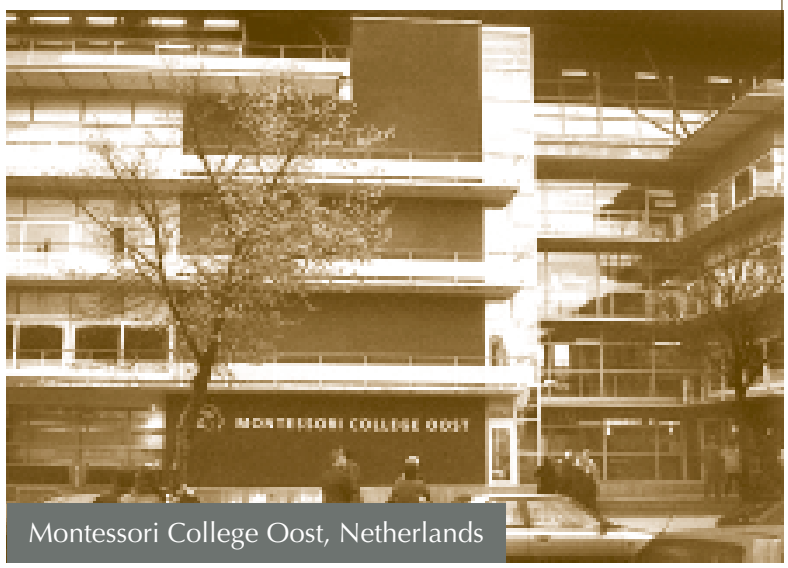

BJ: The Amsterdam Watershed is about developing alternatives, not replacing one approach with another. This is because of the "what if we are wrong" scenario. However, "what if we keep things as they are?" also is a legitimate question. Integral to these questions is the assumption that one size fits all.

This idea of "all or nothing" is carried into other aspects of the question. Ninety percent of what we learn is learned outside of school. I hope parents do not turn their children totally over to the system. A child's learning should never be dependent upon a single approach.

We need to separate what is changing from what stays the same. How we teach is changing but how children learn is not. Learning environments need to enable learning, and therefore the real question is "what, in the past, was an environmental barrier to learning and what enabled learning?" And to further complicate things, this will vary with the mode of learning at any one time. If that is not enough, what about the individual's learning style or appropriate group learning strategies? And I could go on.

One last point. We know we learn by failure and some people say that's the best way. Based on that fact, our schools are not the sole conduit to learning so we should not be fearful of taking risks to improve our learning environments. The greatest risk is to take no risk at all.

Jose Freire da Silva: Based on your experiences, how important are built environments created by architects, how, and in what way, are those environments part of the models under consideration?

BJ: This is a variation on the nature verses nurture argument. It is not an either/or condition and both are fundamentally important. The environment has a significant effect on our behaviour. A basic example is the classroom. Take a roughly $80 \mathrm{~m}^{2}$ space with a three metre ceiling, place a marker board to define the front, send in one adult and 30 kids who have never seen each other, and more often than not the adult will assume control. Place the same people in an 


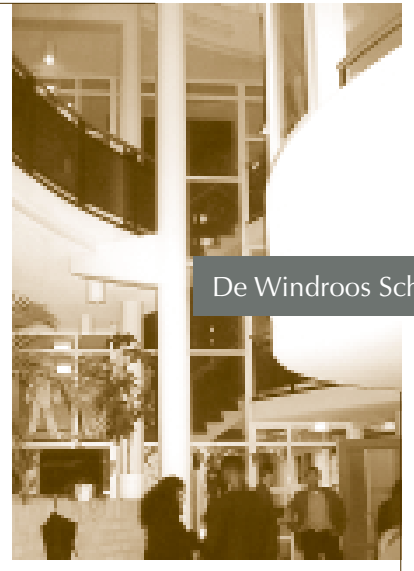

arcade game setting, and the kids will assume control. The environment influences behaviour. However, our knowledge of this is very limited and needs more research.

Sarah Woodhead: Your concept for high schools presented in the early 1990s was an exciting break-the-mould approach to educating students. In that concept, the form and the function are mutually responsive. However, in most case studies derived from that early concept, there seems to be an overstatement of the degree to which school as centre or institution can/should/will cease to exist. Please comment on the role school as a physical place in a community carries meaning within your work.

BJ: The physical place of learning in a community should be symbolic of the meaning that learning has in that community. If the meaning of learning in a particular society is characterised as something special, unique, controlled, elite, then the school should physically reflect this. If the meaning of learning is seen as integral to all aspects in a society, then learning should have presence everywhere. Your question implies that I promote the latter, as if I know what's best. Having worked in a variety of cultures (33 countries and most states) I have learned not to advocate any preconception but only show possibilities.

SW: Bruce, at best your ideas reflect a clear and invigorating sense of what learning should be; at worst, there is sometimes more than a hint of idealist tyranny that ignores many of the subtle but important patterns of humanity. You would do away with the classroom and the school, and while that is certainly alluring and can work in limited circumstance, do you ever see a danger in promoting dramatic change? Do you see your role as provocateur? How far should architects go in adopting your approaches? How sceptical should practitioners be?

BJ: First, one assumes I am promoting dramatic change. I do not promote anything except that people think before they act when making decisions about learning environments. To help them, I share some of the possibilities. Second, do I see myself as provocateur? This is for others to

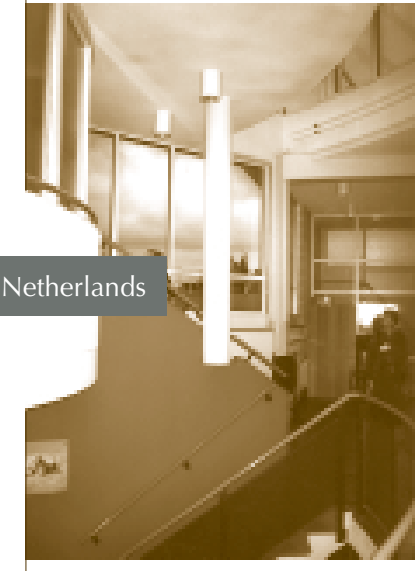

decide. I share ideas. Some people respond by giving those ideas thoughtful consideration. Others, apparently, are provoked. Third, should architects adopt my approaches? School architects ought to be knowledgeable in the numerous possibilities out there. This is also true for school planners and educators. Knowledge is not painful. Finally, how sceptical should practitioners be? Why not ask: how knowledgeable, how inquisitive, how curious, how informed, how excited or even should they be sceptical?

This article by Randall Fielding first appeared in the January/February 2001 issue of the US magazine School Construction News. The interview is posted in its entirety on http://www.designshare.com

Interviewers:

- Randall Fielding, editor, Design Share, Minneapolis, MN, USA; e-mail: fielding@designshare.com

- William Brenner, director, National Clearinghouse for Educational Facilities, Washington, DC, USA; e-mail: bbrenner@nibs.org

- Lia Burgers, B+B E-novations, Netherlands; e-mail: a.bless@chello.nl

- Charles H. Boney, Jr., AIA, Boney Architects, Wilmington, DE, USA; e-mail: cb2@boneyarch.com

- Prakash Nair, president, Urban Educational Facilities for the $21^{\text {st }}$ Century, USA; e-mail: Prakash@designshare.com

- Arnie Glassberg, Unified School District, San Lorenzo, CA, USA; e-mail: ARNIE@sanlorenzousd.k12.ca.us

- F. Andy Simpson, AIA, Pfluger Associates Architects, P.L.L.C., San Antonio, TX, USA; e-mail: andy@pflugerassociates.com

- Jack Lyons, US Department of Education, USA; e-mail: Jack_Lyons@ed.gov

- James E. LaPosta, Jeter, Cook \& Jepson Architects, Hartford, CT, USA; e-mail: laposta@jcj.com

- Jose M. Freire da Silva, Ministry of Education, Lisbon, Portugal; e-mail: jmsilva@degre.min-edu.pt

- Sarah Woodhead, SHW Group, USA; e-mail: sjwoodhead@shwgroup.com 